\title{
Percutaneous Endoscopic Lumbar Foraminoplasty for Resection of Synovial Cyst
}

\author{
Kyung-Chul Choi ${ }^{1}$, Dong Chan Lee ${ }^{1}$, Choon-Keun Park ${ }^{2}$ \\ ${ }^{1}$ Department of Neurosurgery, the Leon Wiltse Memorial Hospital, Anyang, \\ ${ }^{2}$ Department of Neurosurgery, the Leon Wiltse Memorial Hospital, Suwon, Korea
}

Corresponding Author:

Dong Chan Lee, MD

Department of Neurosurgery, The Leon Wiltse Memorial Hospital,

560, Gyeongsu-daero, Dongan-gu, Anyang-si 14112, Korea

Tel: $+82-31-460-1225$

Fax: +82-31-460-1224

E-mail: surgicel@hanmail.net

Received: April 12, 2016

Revised: May 12, 2016

Accepted: May 13, 2016
Synovial cyst is an extradural mass that compresses nerve root or thecal sac. Surgical excision with partial hemilaminectomy and medial facetectomy is commonly used for synovial cyst. Remarkable advancements in endoscopic spinal surgery have led to successful outcomes comparable to conventional open surgery. Here we introduce percutaneous endoscopic lumbar foraminoplasty for resecting synovial cyst as a minimal invasive technique. A 59-year-old woman presented with radicular pain at left $\mathrm{L} 5$ dermatome. Magnetic resonance images demonstrated a synovial cyst at left L4-5 facet joint and degenerative spondylolisthesis on L4-5. Under endoscopy, synovial cyst was removed by piecemeal method after transforaminal endoscopic foraminoplasty that removed part of superior facet. Her symptoms were relieved and the patient was discharged the next day. Therefore, percutaneous endoscopic lumbar foraminoplasty can be used as a minimally invasive surgical option for synovial cyst. It may provide less traumatization and affect less postoperative instability.

Key Words: Synovial cyst, Spondylolisthesis, Percutaneous endoscopic lumbar foraminoplasty

\section{INTRODUCTION}

Synovial cyst compressing nerve root was first reported in $1950^{24)}$. Synovial cyst of facet joint can cause radicular pain and neurogenic claudication ${ }^{5,19)}$. Unresponsive to conservative treatment, surgical removal is regarded as a definite treatment for persistent radicular pain or neurologic deficit. Whether additional fusion is necessary remains controversial. Remarkable advancements in endoscopic techniques and instrumentation have led to successful outcomes comparable to conventional open surgery ${ }^{1,8,17,20)}$. Recently, several minimal invasive techniques including micro-endoscopic assisted approach and percutaneous interlaminar approach have been applied to remove synovial cyst ${ }^{13,16)}$. Here we introduce percutaneous endoscopic lumbar foraminoplasty for resecting synovial cyst in the spinal canal as a minimal invasive technique.

\section{CASE REPORT}

A 59-year-old woman presented with radicular pain in the left leg from buttock to the lateral of thigh and leg. There was objective weakness of the great-toe dorsiflexion. On manual muscle test, it was graded as 4. Radiography (Fig. 1A) showed grade 1 degenerative spondylolisthesis at L4-5. Magnetic resonance (MR) images (Fig. 1B and 1C) showed synovial cyst at left L4-5 facet joint compressing the neural structures in the spinal canal. Computed tomography (Fig. 1D) showed round mass juxta at left facet joint. The radiating pain sustained after epidural steroid injection. Therefore, we planned cyst removal with endoscopic technique.

This procedure was performed under local anesthesia with the patient lying in the prone position. The skin entry point was $13 \mathrm{~cm}$ from the midline at $L 4-5$ disc space. After infiltrating the entry point with local anesthetics, an 18-gauge spinal needle was introduced under the guidance of fluoroscopic imaging. The target point of the spinal needle was the medial pedicular line on the anteroposterior image and the posterior vertebral line on the lateral image. Subsequently, an epidurography was performed using contrast media to confirm the location of the exiting and the traversing root. The following steps were then performed: a guide wire was inserted through the spinal needle; the spinal needle was removed; a small incision was made in the skin at the entry site; a tapered cannulated obturator was inserted along the guide wire. When the obturator touched the annulus, a bevel-ended working cannula was inserted along the obturator. The cannula was located outside the foramen and 
lateral border of the facet joint. The superior part of facet joint was removed by endoscopic drill (Primado 2, Nakanishi inc, Japan) (Fig. 2A). From outside foramen to inside foramen, partial part of the facet joint and foraminal ligament were removed by a drill, a cutting forcep, and an endoscopic kerrison punch. While engaging working cannula to the medial foraminal zone to undercut the superior facet and remove yellow ligament,
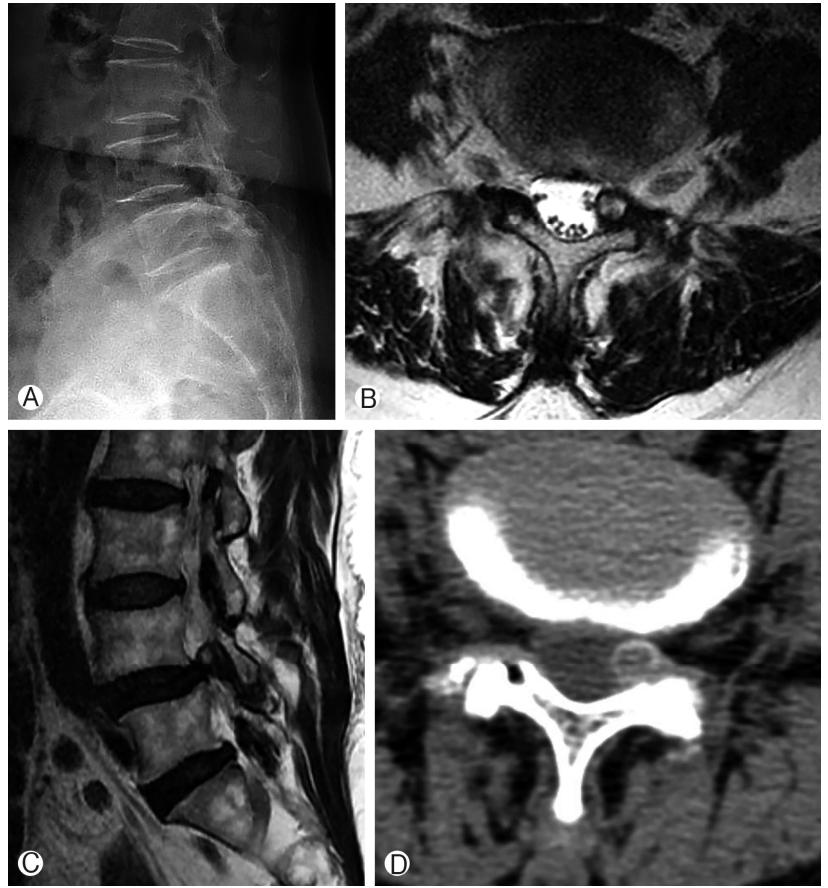

Fig. 1. Lateral Radiography (A) showing grade I spondylolisthesis. Magnetic Resonance (MR) images (B), C) showing synovial cyst compressing the thecal sac. Computed tomography (D) showing well-demarcated round mass juxta facet joint. white-yellowish mass (Fig. 2B) was encountered. With meticulous bleeding control, the mass was removed by piecemeal. After removing the mass, neural structures were released (Fig. 2C). After the procedure, the pain was improved. Postoperative MR image revealed complete removal of synovial cyst (Fig. 3). The patient was discharged the next day.
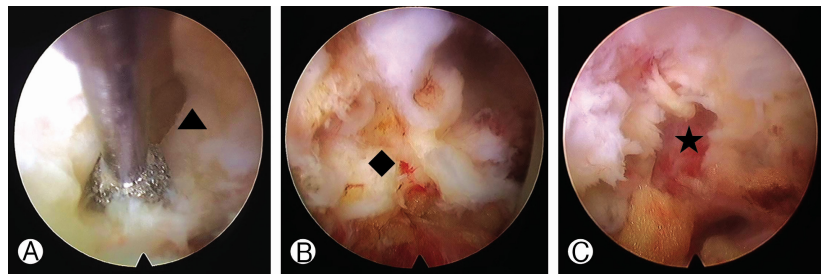

Fig. 2. In the endoscopic view, partial part of superior facet (A) was removed with endoscopic diamond drill (A). After removing the superior facet, yellowish mass $(\bullet)$ was encountered, which was synovial cyst (B). After removing the mass with piecemeal method, neural structure $(\star)$ was found (C).
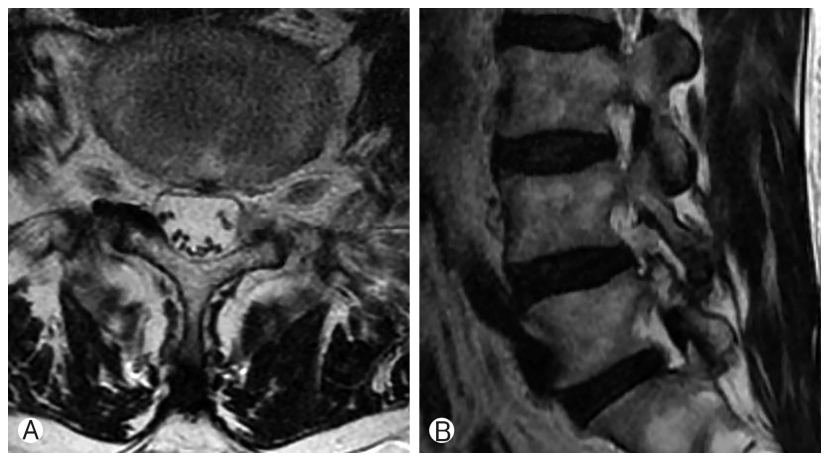

Fig. 3. Postoperative axial (A) and parasagittal (B) MR images showing the removal of synovial cyst with partial removal of the superior facet.

Table 1. Clinical results of endoscopic foraminoplasty

\begin{tabular}{|c|c|c|c|c|c|c|c|}
\hline Authors & $\begin{array}{l}\text { No. of } \\
\text { patients }\end{array}$ & Disease & Technique & Aim & Instruments & $\begin{array}{l}\text { Success } \\
\text { rate }\end{array}$ & Complication \\
\hline Knight et al. ${ }^{15)}$ & 250 & $\begin{array}{l}\text { foraminal } \\
\text { stenosis }\end{array}$ & $\begin{array}{l}\text { endoscopic } \\
\text { foraminoplasty }\end{array}$ & $\begin{array}{l}\text { decompression of } \\
\text { exiting nerve root and } \\
\text { traversing nerve root }\end{array}$ & laser & $73 \%$ & $\begin{array}{l}1 \text { foot drop, } \\
5 \% \text { revision }\end{array}$ \\
\hline Ahn et al." & 33 & $\begin{array}{l}\text { foraminal } \\
\text { stenosis }\end{array}$ & $\begin{array}{l}\text { endoscopic } \\
\text { foraminotomy }\end{array}$ & $\begin{array}{l}\text { decompression of } \\
\text { exiting nerve root }\end{array}$ & $\begin{array}{l}\text { endoscopic } \\
\text { drill, laser, } \\
\text { micropunch }\end{array}$ & $82 \%$ & $\begin{array}{l}6.1 \% \text { dysesthesia, } \\
3 \% \text { revision }\end{array}$ \\
\hline $\begin{array}{l}\text { Schubert and } \\
\text { Hoogland }^{23)}\end{array}$ & 558 & $\begin{array}{c}\text { lumbar disc } \\
\text { herniation }\end{array}$ & $\begin{array}{l}\text { endoscopic } \\
\text { foraminoplasty }\end{array}$ & $\begin{array}{l}\text { widening of foraminal } \\
\text { zone }\end{array}$ & reamer & $95 \%$ & $\begin{array}{l}0.5 \% \text { transient } \\
\text { paresthesia, } \\
3.6 \% \text { revision }\end{array}$ \\
\hline Choi et al. ${ }^{7)}$ & 59 & $\begin{array}{l}\text { migrated disc } \\
\text { herniation }\end{array}$ & $\begin{array}{l}\text { endoscopic } \\
\text { foraminoplasty }\end{array}$ & $\begin{array}{l}\text { widening of foraminal } \\
\text { zone and partial } \\
\text { pediculectomy }\end{array}$ & $\begin{array}{l}\text { endoscopic } \\
\text { drill }\end{array}$ & $91 \%$ & 8.5\% revision \\
\hline Choi et al. ${ }^{9)}$ & 19 & $\begin{array}{l}\text { disc herniation } \\
\text { at L5-S1 with } \\
\text { high iliac crest }\end{array}$ & $\begin{array}{l}\text { endoscopic } \\
\text { foraminoplasty }\end{array}$ & $\begin{array}{l}\text { widening of foraminal } \\
\text { zone }\end{array}$ & reamer & $92 \%$ & $2 \%$ revision \\
\hline
\end{tabular}




\section{DISCUSSION}

Synovial cyst is an extradural mass that compresses nerve root or thecal sac, ${ }^{5,19)}$. Synovial cyst usually presents radiculopathy. It can also cause neurogenic claudication with pre-existing spinal stenosis ${ }^{12,18)}$. It is associated with degenerative changes, causing fluid extrusion from the joint capsule. It is commonly found in spondylolisthesis, osteoarthritis, and disc degeneration in the mid- $60 \mathrm{~s}^{4}$. The incidence of synovial cyst is reported to be $2.3 \%{ }^{10,22)}$. L4-5 level is the most affected segment ${ }^{5}$. It might be associated with mobility at that level. The natural history of the synovial cyst is not well established. Conservative treatments for synovial cysts have been reported to be less effective". Percutaneous aspiration of the cyst also has higher recurrence and failure rates ${ }^{11)}$. Surgical excision with partial hemilaminectomy and medial facetectomy is a common procedure for synovial cyst. Decompression alone can achieve successful results. For example, Lyon et al. have achieved $91 \%$ of good outcomes in 134 patients $^{18)}$. According to literature, cystic recurrence rate is about $2 \%$ after decompression alone ${ }^{5}$. However, recurrent back pain occurs in $20 \%$ of cases during the follow-up. It may be caused by segmental instability, hypermobility, and progression of degenerative changes. Extensive bone removal is associated with postoperative instability ${ }^{211}$. For spondylolisthesis after open excision, fusion surgery is required for $1.8 \%$ to $6 \%$ of patients ${ }^{34,18)}$. Whether fusion surgery has better outcome than decompression alone remains controversial although fusion surgery decreases recurrent back pain ${ }^{14,25)}$. Minimal invasive techniques for synovial cyst include micro-endoscopic assisted cyst removal, contralateral approach presenving facet joint, and endoscopic interlaminar approach ${ }^{2,13,16)}$. Komp et al. have reported successful results of full-endoscopic synovial cyst removal ${ }^{16)}$. They have solved synovial cyst in the spinal canal with interlaminar approach as in conventional posterior approach. Transforaminal approach is applied only to foraminal/extraforaminal synovial cyst. Epidural scarring can be reduced in endoscopic techniques based on postoperative MR images and revision surgery.

Knight et al. ${ }^{15)}$ have introduced laser-assisted foraminoplasty to ablate foraminal ligament and osteophytes (Table 1). Foraminoplasty has been applied to down-migrated disc herniation or sequestrated disc to remove superior facet and partial pedi$\mathrm{Cle}^{7,23)}$. L5-S1 disc herniation with high iliac crest needs foraminoplasty for engaging working cannula ${ }^{9}$. Ahn et al. ${ }^{11}$ have reported endoscopic foraminotomy for foraminal stenosis using an endoscopic drill, a side-firing laser, and a micropunch. This technique enables the visualization and the mobilization of both traversing nerve root and exiting nerve root under endoscopy to remove foraminal ligament, superior facet, and herniated disc. In this case, we were concerned that the posterior approach might require wide bone removal including large laminectomy and medial facetectomy which might cause instability at the index level. Transforaminal endoscopic approach might make it safer to remove synovial cyst, thus preserving facet joint as much as possible. Under endoscopy, it is safe to remove adequate bone and synovial cyst using an endoscopic diamond drill and endoscopic instruments. Furthermore, the transforaminal endoscopic approach is advantageous in that synovial cyst can be removed without needing the manipulation of neural structures. It might be able to reduce surgery-induced segmental instability. Theoretically, it has several drawbacks such as steep learning curve, results depending on surgeon, uncertainty of sufficient decompression, and difficulty in suturing a dural tear.

\section{CONCLUSION}

Percutaneous endoscopic lumbar foraminoplasty can be used as a minimally invasive surgical option for synovial cyst. It may provide less traumatization and affect less postoperative instability.

\section{REFERENCES}

1. Ahn Y, Oh HK, Kim H, Lee SH, Lee HN: Percutaneous endoscopic lumbar foraminotomy: an advanced surgical technique and clinical outcomes. Neurosurgery 75:124-133; discussion 132123, 2014

2. Alimi M, Hofstetter CP, Pyo SY, Paulo D, Hartl R: Minimally invasive laminectomy for lumbar spinal stenosis in patients with and without preoperative spondylolisthesis: clinical outcome and reoperation rates. J Neurosurg Spine 22:339-352, 2015

3. Banning CS, Thorell WE, Leibrock LG: Patient outcome after resection of lumbar juxtafacet cysts. Spine (Phila $\mathrm{Pa} 1976$ ) 26: 969-972, 2001

4. Boviatsis EJ, Stavrinou LC, Kouyialis AT, Gavra MM, Stavrinou PC, Themistokleous M, et al: Spinal synovial cysts: pathogenesis, diagnosis and surgical treatment in a series of seven cases and literature review. Eur Spine J 17:831-837, 2008

5. Bydon A, Xu R, Parker SL, McGirt MJ, Bydon M, Gokaslan $\mathrm{ZL}$, et al: Recurrent back and leg pain and cyst reformation after surgical resection of spinal synovial cysts: systematic review of reported postoperative outcomes. Spine J 10:820-826, 2010

6. Bydon M, Papadimitriou K, Witham T, Wolinsky JP, Sciubba D, Gokaslan Z, et al: Treatment of spinal synovial cysts. World Neurosurg 79:375-380, 2013

7. Choi G, Lee SH, Lokhande P, Kong BJ, Shim CS, Jung B, et al: Percutaneous endoscopic approach for highly migrated intracanal disc herniations by foraminoplastic technique using rigid working channel endoscope. Spine (Phila Pa 1976) 33:E508515, 2008

8. Choi KC, Kim JS, Park CK: Percutaneous Endoscopic Lumbar Discectomy as an Alternative to Open Lumbar Microdiscectomy for Large Lumbar Disc Herniation. Pain Physician 19:E291-300, 2016

9. Choi KC, Park CK: Percutaneous Endoscopic Lumbar Discectomy for L5-S1 Disc Herniation: Consideration of the Relation between the Iliac Crest and L5-S1 Disc. Pain Physician 19:E301308, 2016

10. Doyle AJ, Merrilees M: Synovial cysts of the lumbar facet joints in a symptomatic population: prevalence on magnetic resonance imaging. Spine (Phila Pa 1976) 29:874-878, 2004

11. Epstein NE, Baisden J: The diagnosis and management of syno- 
vial cysts: Efficacy of surgery versus cyst aspiration. Surg Neurol Int 3:S157-166, 2012

12. Hsu KY, Zucherman JF, Shea WJ, Jeffrey RA: Lumbar intraspinal synovial and ganglion cysts (facet cysts). Ten-year experience in evaluation and treatment. Spine (Phila Pa 1976) 20:80-89, 1995

13. Ishii K, Matsumoto M, Watanabe K, Nakamura M, Chiba K, Toyama Y: Endoscopic resection of cystic lesions in the lumbar spinal canal: a report of two cases. Minim Invasive Neurosurg 48:240-243, 2005

14. Khan AM, Synnot K, Cammisa FP, Girardi FP: Lumbar synovial cysts of the spine: an evaluation of surgical outcome. J Spinal Disord Tech 18:127-131, 2005

15. Knight MT, Goswami A, Patko JT, Buxton N: Endoscopic foraminoplasty: a prospective study on 250 consecutive patients with independent evaluation. J Clin Laser Med Surg 19:73-81, 2001

16. Komp M, Hahn P, Ozdemir S, Merk H, Kasch R, Godolias G, et al: Operation of lumbar zygoapophyseal joint cysts using a fullendoscopic interlaminar and transforaminal approach: prospective 2-year results of 74 patients. Surg Innov 21:605-614, 2014

17. Lee SH, Chung SE, Ahn Y, Kim TH, Park JY, Shin SW: Comparative radiologic evaluation of percutaneous endoscopic lumbar discectomy and open microdiscectomy: a matched cohort analysis. Mt Sinai J Med 73:795-801, 2006

18. Lyons MK, Atkinson JL, Wharen RE, Deen HG, Zimmerman RS, Lemens SM: Surgical evaluation and management of lumbar synovial cysts: the Mayo Clinic experience. J Neurosurg 93:5357, 2000

19. Radatz M, Jakubowski J, Cooper J, Powell T: Synovial cysts of the lumbar spine: a review. Br J Neurosurg 11:520-524, 1997

20. Ruetten S, Komp M, Merk H, Godolias G: Full-endoscopic interlaminar and transforaminal lumbar discectomy versus conventional microsurgical technique: a prospective, randomized, controlled study. Spine (Phila Pa 1976) 33:931-939, 2008

21. Sabo RA, Tracy PT, Weinger JM: A series of 60 juxtafacet cysts: clinical presentation, the role of spinal instability, and treatment. J Neurosurg 85:560-565, 1996

22. Scholz C, Hubbe U, Kogias E, Klingler JH: Incomplete resection of lumbar synovial cysts - Evaluating the risk of recurrence. Clin Neurol Neurosurg 136:29-32, 2015

23. Schubert M, Hoogland T: Endoscopic transforaminal nucleotomy with foraminoplasty for lumbar disk herniation. Oper Orthop Traumatol 17:641-661, 2005

24. Vosschulte K, Borger G: [The inflammatory processes in sciatica due to intervertebral disk hernia]. Med Monatsschr 4:371-375, 1950

25. Xu R, McGirt MJ, Parker SL, Bydon M, Olivi A, Wolinsky JP, et al: Factors associated with recurrent back pain and cyst recurrence after surgical resection of one hundred ninety-five spinal synovial cysts: analysis of one hundred sixty-seven consecutive cases. Spine (Phila Pa 1976) 35:1044-1053, 2010 